\title{
Fair Access
}

\section{There has been sound and fury in the Open Access movement over the last few months. On December 16, 2011, The Research Works Act (RWA) was introduced in the U.S. House of Representatives. The bill contained}

provisions to prohibit open-access mandates for federally funded research, effectively nullifying the $\mathrm{Na}$ tional Institutes of Health's policy that requires taxpayer-funded research to be freely accessible online. Many scholarly publishers, including the Association of American Publishers (AAP), expressed support for the bill.

The reaction to the bill and its support by scholarly publishers has been one of sheer outrage, with headlines such as "Academic Publishers Have Become the Enemies of Science." On January 21,2012 , renowned British mathematician Timothy Gowers declared a boycott on Elsevier, a major scholarly publisher, in a detailed blog posting. The boycott movement then took off, with over 8,000 scientists having joined it so far. By the end of February, Elsevier had withdrawn its support of RWA, and its sponsors in U.S. House of Representatives announced that RWA "has exhausted the useful role it can play in the debate."

Now that things have quieted down a bit, we can revisit the arguments for open access, which I discussed first in July 2009, in "Open, Closed, or Clopen Access?" The basic question I would like to address again is what ACM's stance should be with respect to openaccess publishing models. (As pointed out in the July 2009 letter, ACM is a Green-Open-Access publisher.)

The arguments in favor of open access have evolved somewhat since the movement emerged about a decade ago. Early arguments talked about broad dissemination of information, under the slogan "information wants to be free." Recent arguments have focused on fairness, as expressed in the headline "Congress Considers Paywalling Science You Already Paid For." But one should not conflate the cost of carrying out research with the cost of publishing the results. Furthermore, universities and academic researchers profit from intellectual property developed under federal funding, and I see no outrage about that.

The real issue seems to me to be the divergence of interests between authors and publishers. Authors of scholarly articles would like to see them disseminated as broadly as possible, while publishers would like to cover the costs of publishing and, possibly, make some profit. This is a true divergence of interests. When it comes to commercial publishers, this divergence, in my opinion, simply cannot be bridged, which explains the outrage directed at Elsevier. As I said in 2009, "Why should for-profit corporations receive products and labor essentially for free?"

In the case of publishing by a professional association, such as ACM, the authors, as ACM members, are essentially also the publishers. Thus, it is up to the association to resolve the tension between the desire for the broadest possible dissemination and the need to cover the cost of publishing. Finding the right balance is one of the major issues the ACM Publication Board deals with on a regular basis. (See "ACM's Copyright Policy" in the October 2011 issue of Communications.) The principle guiding the Publi- cation Board is that of fair access.

What is fair access? First and foremost, articles published by ACM are broadly available at a very reasonable cost. I recently computed the cost per download at my home institution for articles from the ACM Digital Library, and compared it to the analogous cost for computing-research articles from commercial publishers. The ACM articles were less expensive by at least two orders of magnitude (100x)! Second, pricing should also take into account the readers' ability to pay, which means there should be special pricing for students and institutions in developing countries. Finally, ACM allows self-archiving by authors, and has recently introduced the Author-Izer service, which enables ACM authors to generate and post links on either their personal page or institutional repository for visitors to download the definitive version of their articles from the ACM Digital Library at no charge.

In my opinion, fair access strikes a reasonable compromise between dissemination and covering publishing costs. Other compromises are also possible. For example, ACM could divert funds from other activities, or increase its membership dues and use the additional income to cover publishing costs. ACM could also adopt the authorpays model of most open-access publishers and ask authors to pay publishing fees to cover the cost of publishing. In either case, the decision is up to $u s$ : ACM members, authors, publishers.

Moshe Y. Vardi, EDITOR-IN-CHIE F 